Bull. Mater. Sci., Vol. 3, Number 1, February 1981, pp. 37-55. (C) Printed in India.

\title{
Computation and application of local solidification times of grey cast iron cast in metallic moulds
}

\author{
MALUR N SRINIVASAN \\ Department of Mechanical Engineoring, Indian Institute of Science, \\ Bangalore 560012, India
}

MS received 5 August 1980

\begin{abstract}
Heat conduction equations applicable to the solidification of grey cast iron cast in moulds of the same material were solved for the cases of plate and cylindrical shaped castings made by pouring the metal at different temperatures into moulds of different wall thicknesses preheated to different temperatures, when the heat transfer coefficient at the casting-mould interface was assumed to have different values. An explicit finite difference method was used to solve the equations- with the aid of a digital computer. Local solidification times at different nodal points were determined from the solutions and a relationship between the local solidification time and the location in a 'casting'. was established. The application of local solidification times for predicting the microstructure and estimating the ultimate tensile strength of these "castings" cast in metallic moulds has been demonstrated.

Keywords. Permanent moulding; grey cast iron; cooling rate; solidification; finite difference method; heat conduction; undercooled graphite; ftake graphite; ferrite; pearlito, tonsilo strength.
\end{abstract}

\section{Introduction}

The application of permanent moulding process to the production of cast iron castings has been rather limited despite the many advantages offered by this process as compared to sand casting process. One of the important reasons for this situation is the difficulty in controlling the structure and properties of permanent mould cast iron castings in view of their extreme sensitivity to the composition, the cooling rate of the casting and the melt treatment, if any. Knowledge of the influence of these factors upon the structure and properties of the castings would be very helpiul in obviating this difficulty. Since it is known that the structure and properties in the as-cast state are consequences of the solidification process, it would be of value to understand the effect of composition, cooling rate and melt treatment upon the solidification of castings. Thermal analysis of castings has been recognised as a valuable tool to provide irformation on these aspects.

Thermal analysis can be carried out using both experimental and analytical techniques. While experimental methods are well-suited for generating information on the effects of composition and melt treatment in a small volume of 
material, they are as a rule expensive to provide information on the effect of cooling rate in different parts of a casting. An additional difficulty is the possibility of the solidification mechanism being altered considerably with the use of too many sensory devices in different parts of the casting. On the other hand the effect of cooling rate can be adequately considered in an analytical model provided the physical conditions prevailing during solidification of the casting are satisfactorily taken into account in the analytical model. It has been recognised that numerical methods are well-suited for this purpose.

In earlier experimental work of the present author and his associates (Rama Prasad et al 1980; Rama Prasad 1976) relationships have been established between the total solidification time of a permanent mould grey cast iron casting, and the structure and tensile strength of the casting. The total solidification time in each case was measured experimentally and for the reason already mentioned it was not possible to assess the local solidification times at diffrent parts of the casting using this experimental technique. However, if the latter information is known, it would be possible to estimate the magnitude of the tensile strength and predict the microstructure at different locations in the casting, from the relationship established experimentally. With this in view computation of the local solidification times of various permanent mould grey cast iron castings was carried out with the aid of a digital computer, using a finite-difference network.

\section{Statement and solution of the problem}

Although details have been published earlier (Srinivasan 1975) they are again presented here for clarity. The alloy chosen for this study is hypereutectic cast iron with a carbon equivalence of $4 \cdot 7$ (which is known to be suitable for producing chill-free castings) cast into grey cast iron moulds without any treatment. The variable affecting the cooling rate of castings are as follows :

Casting shape

Casting size

\section{Mould wall thickness}

Pouring temperature $\left({ }^{\circ} \mathrm{C}\right)$

Initial mould temperature $\left({ }^{\circ} \mathrm{C}\right)$

Heat transfer coefficient at the cooling-mould interface
Plate and cylinder

$1 \cdot 27,1 \cdot 90,2 \cdot 54$, and $3 \cdot 18 \mathrm{~cm}$ thick plates

$3.84,6.36,8.88$ and $11.40 \mathrm{~cm}$ diameter cylinders

$1 \cdot 28,1 \cdot 92$ and $2 \cdot 56 \mathrm{~cm}$.

$\begin{array}{rrr}\text { I set } & \text { II set } & \text { III set } \\ 1350 & 1300 & 1250 \\ 250 & 200 & 150\end{array}$

$0.01,0.02,0.03,0.040 .05 \mathrm{cal} / \mathrm{sec} . \mathrm{cm}^{2} \mathrm{C}$

The initial conditions are :

(i) The casting, when completely filled in the mould, is at a uniform temperature of 1350,1300 or $1250^{\circ} \mathrm{C}$.

(ii) The initial mould temperature when the casting is completely filled is $250^{\circ} \mathrm{C}$ when the metal temperature is $1350^{\circ} \mathrm{C}, 200^{\circ} \mathrm{C}$ when the metal temperature is $1300^{\circ} \mathrm{C}$ and $150^{\circ} \mathrm{C}$ when the metal temperature is $1250^{\circ} \mathrm{C}$. 
The boundary conditions are :

(i) Heat flow across the casting-mould interface is governed by a heat transfer coefficient $h$.

(ii) The outer surface of the mould loses heat by convection and radiation to the surrounding atmosphere.

The heat conduction equations considered are :

$$
\frac{\partial \theta}{\partial t}=a \frac{\partial^{2} \theta}{\partial x^{2}} \text { for plates }
$$

and $\frac{\partial \theta}{\partial t}=a\left\{\frac{\partial^{2} \theta}{\partial r^{2}}+\frac{1}{r} \frac{\partial \theta}{\partial r}\right\}$ for cylinders.

Typical finite difference networks employed are shown in figure 1. The finite difference equations applicable in each case are as follows.

$$
\theta N(I)=[M(I)\{\theta(I+1)+\theta(I-1\}]+[\{1-2 M(I)\} \theta(I)]
$$

for the interior points in the casting and the mould

$$
\begin{aligned}
\theta N(C)= & \theta(C)+[2 M(C)\{\theta(C-1)-\theta(C\}] \\
& -\left[\frac{2 h \Delta x \cdot M(C)}{K(C)}\{\theta(C)-\theta(C+1)\}\right]
\end{aligned}
$$

for the outer surface of the casting.

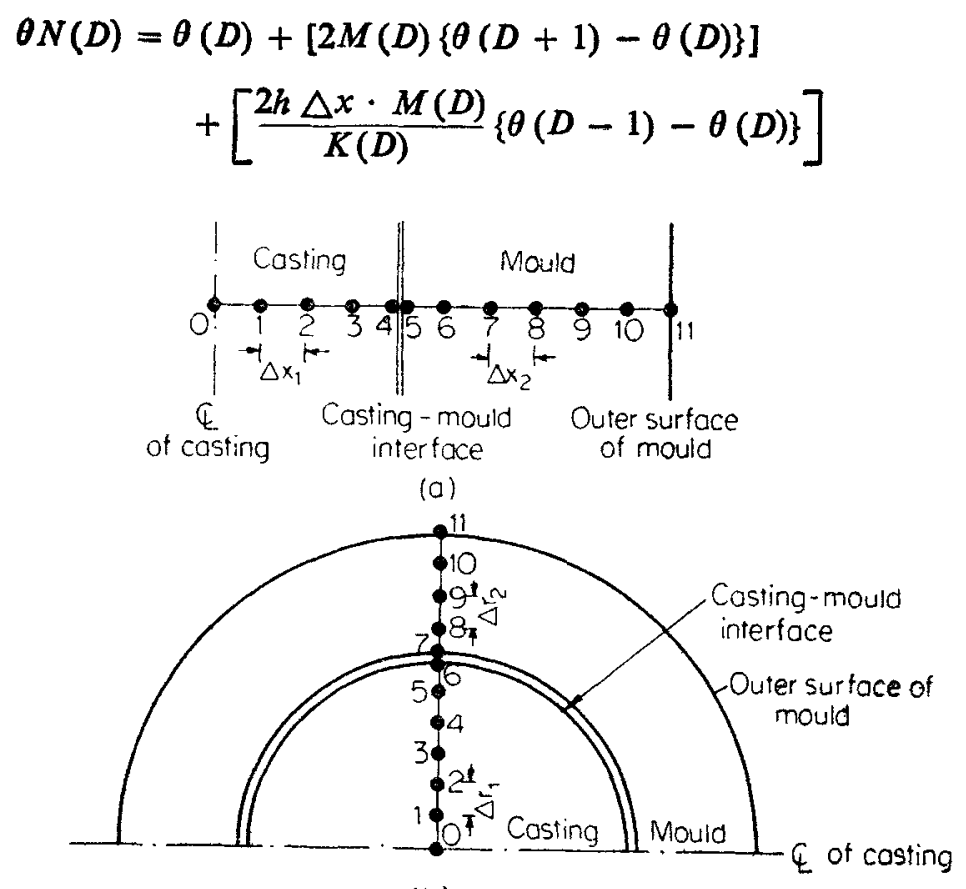

(b)

Figure 1. Schematic representation of typical finite difference network. 
for the inner surface of the mould, and

$$
\begin{aligned}
\theta N(L)= & M(L)\left[2 \theta(L-1)-\left\{\frac{2 h_{C, R} x}{K(L)}(\theta(L)-A T)\right\}\right] \\
& +[\{1-2 M(L)\} \theta(L)]
\end{aligned}
$$

or the outer surface of the mould.

Cylinder shaped castings

The respective equations are :

$$
\begin{aligned}
\theta N(I)=M(I) & {\left[\left\{\frac{2 I+1}{2 I} \theta(I+1)\right\}+\left\{\frac{2 I-1}{2 I} \theta(I-1)\right\}\right] } \\
+ & {[\{1-2 M(I)\} \theta(I)] }
\end{aligned}
$$

corresponding to equation (3),

$$
\begin{aligned}
\theta N(C)=\theta(C)+[2 M(C)\{\theta(C-1)-\theta(C)\}] \\
-\left[\frac{2 C+1}{2 C} \cdot \frac{2 h \Delta^{r} M(C)}{K(C)}\{\theta(C)-\theta(C+1)\}\right]
\end{aligned}
$$

corresponding to equation (4),

$$
\begin{aligned}
& \theta N(D)=\theta(D)+[2 M(D)\{\theta(D+1)-\theta(D)\}] \\
&+ {\left[\frac{2 D-1}{2 D} \cdot \frac{2 h \Delta r M(D)}{K(D)}\{\theta(D-1)-\theta(D)\}\right] }
\end{aligned}
$$

corresponding to equation (5), and

$$
\begin{aligned}
\theta N(L)= & M(L)\left[2 \theta(L-1)-\left\{\frac{2 L+1}{2 L} \cdot \frac{2 h_{C, R} \Delta r}{K(L)}(\theta(L)-A T)\right\}\right] \\
& +[\{1-2 M(L)\} \theta(L)]
\end{aligned}
$$

corresponding to equation (6).

In these equations, thermal property values obtained from Angus (1960) are substituted according to the values of temperatures and the modulus at each mesh point is determined from a knowledge of the thermal properties as well as the chosen spatial and time incremental values.

The heat transfer coefficient at the casting-mould interface is chosen to have five different values $(0.01,0.02,0.03,0.04$ and 0.05 C.G.S. units) for each casting-mould combination. In practical problems this value is dependent upon many factors such as the net contraction or expansion of the casting during solidification, the expansion of the mould and the type of mould coating employed etc. However, the range c'losen fairly represents the values encountered in practice.

It is assumed in the present problem that there is no liquidus arrest and that eutectic freezing occurs at a constant temperature of $1150^{\circ} \mathrm{C}$. At the eutectic temperature, the temperature at each nodal point is made to remain constant until 
the latent heat is liberated according to the method originally suggested by Eyers et al (1946) and Dusinberre (1949).

The computer program was written in Fortran IV language and calculations were performed mainly with the aid of IBM $360 / 44$ computer at the Indian Institute of Science. In all, 360 "castings" were examined.

\section{Results and discussion}

In figure 2 typical temperature variation curves are shown at different locations in a given "casting" from which the solidification time at each location was determined. In the author's earlier publication (Srinivasan 1975) the following observations had been made on total solidification time (solidification time of the last part of the casting to solidify) in respect of the 120 "castings" examined in that paper.

(i) In a given casting the total solidification time decreases as the heat transfer coefficient at the casting-mould interface increases, but this decrease is less marked at higher values of the coefficient.

(ii) When solidifying in a mould of a given wall thickness and for a given value of the heat transfer coefficient, the total solidification time of a plate" shaped casting is higher than that of a compatible cylindrical casting.

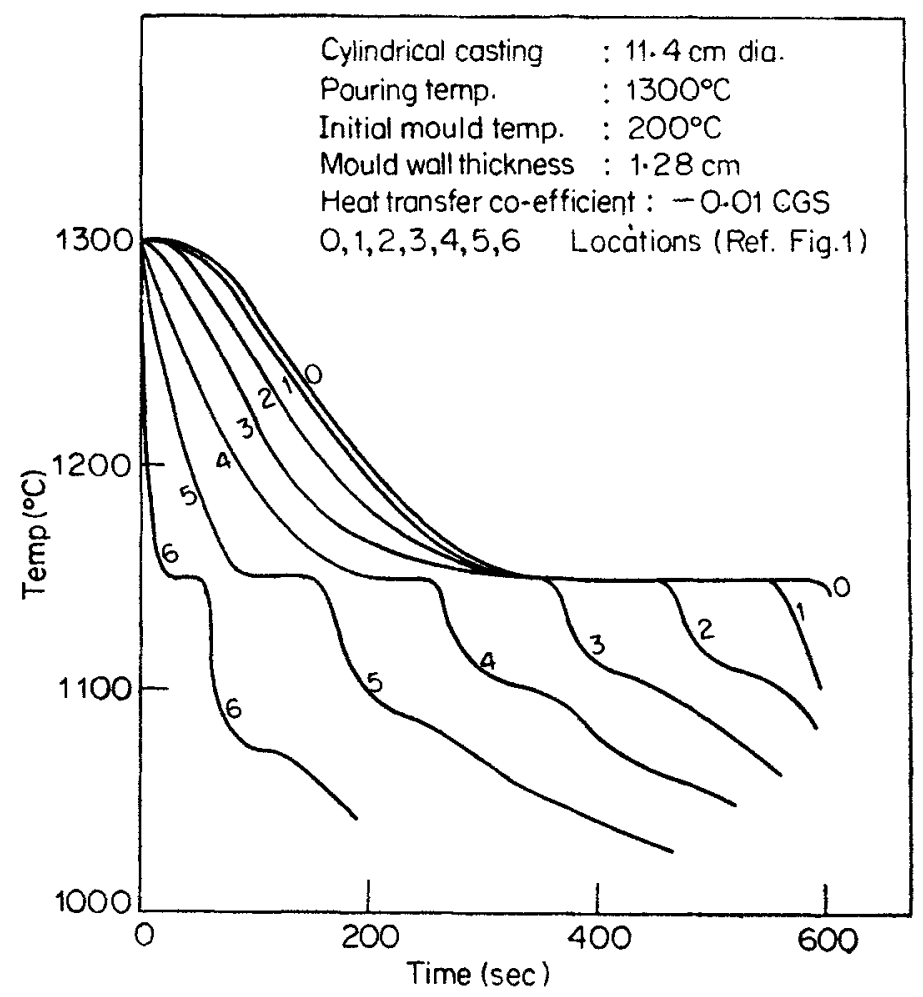

Figure 2. Casting cooling curves. 
(iii) The extent of decrease in solidification time when the shape is changed from plate to cylinder is higher in the case of thin-walled moulds compared to thick-walled moulds.

These observations are equally valid in respect of the additional 240 "castings" examined in this paper. In addition, the following observation is also found to be valid.

In a given casting the total solidification time decreases as the pouring temperature and the initial mould temperature are decreased, at a given value of the heat transfer coefficient.

In the earlier paper (Srinivasan 1975) the local solidification times at different locations in each casting had not been considered and this aspect has been examined in detail in the present paper.

Figure 3 shows typical plots of the local solidification times with respect to the relevant locations. It is observed that appreciable changes in slope occur near the centre of the castings in all cases and near the surface of the castings in some cases. However, in the interior region of the casting, the relationship between the local solidification time and the distance of that location from the surface of the casting is approximately linear in all the "castings" examined. The equations of these linear relationships $\left(T=C_{1} l+C_{L}\right)$ were determined by the least square method and the values of the slopes and intercepts have been tabulated in tables 1 to 6 . The deviations of the solidification times at the surface

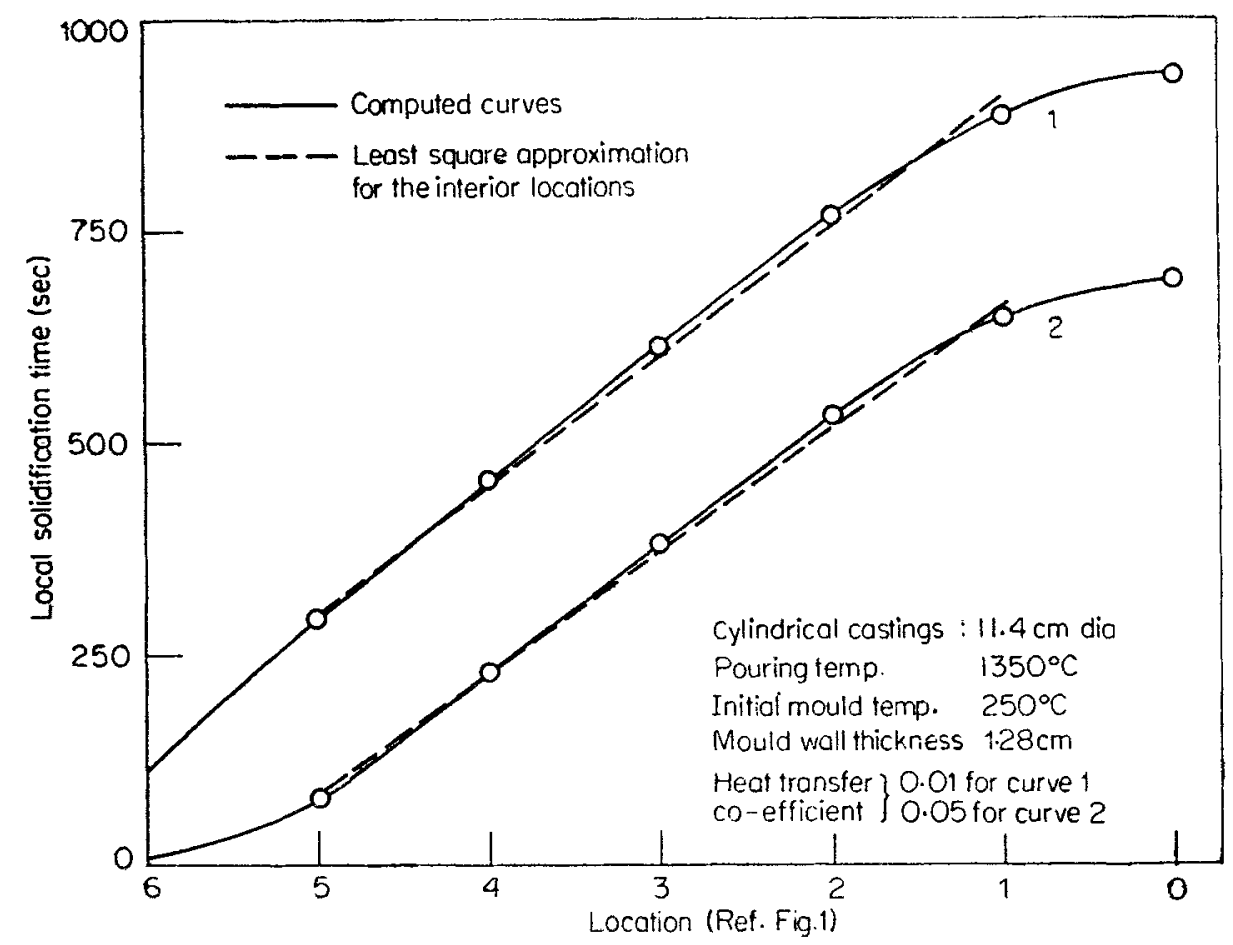

Figure 3. Solidification times at different locations in the castings. 


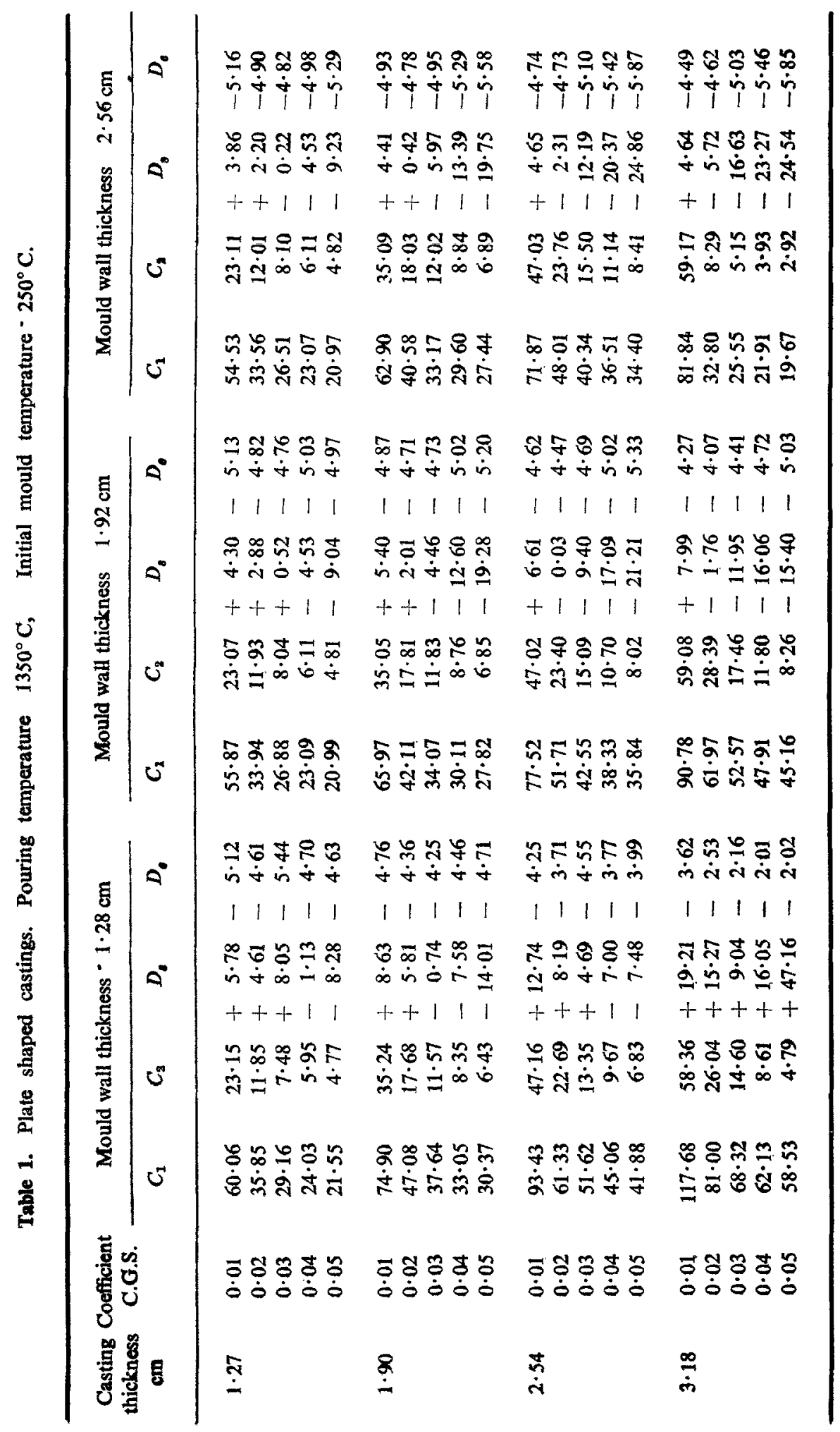




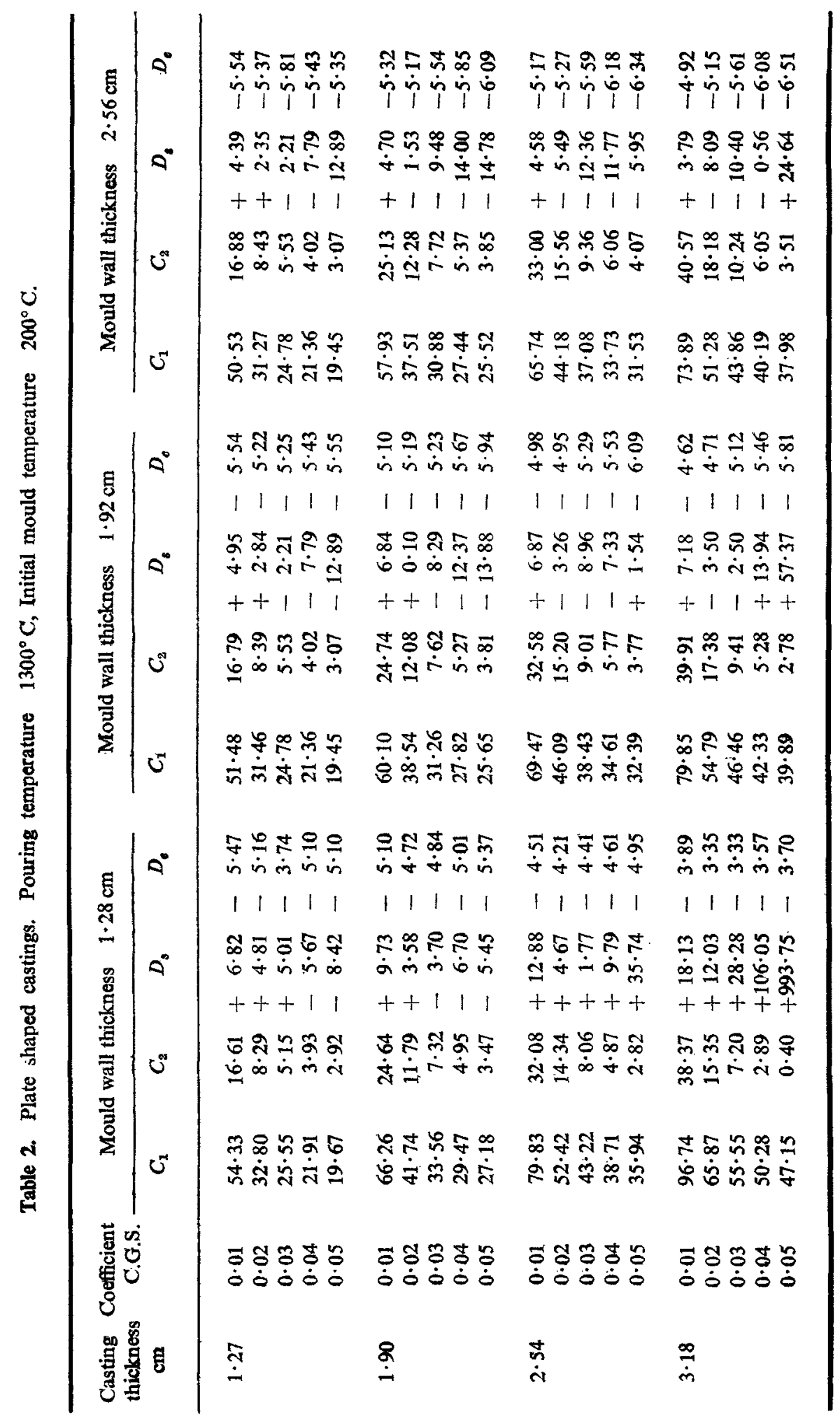




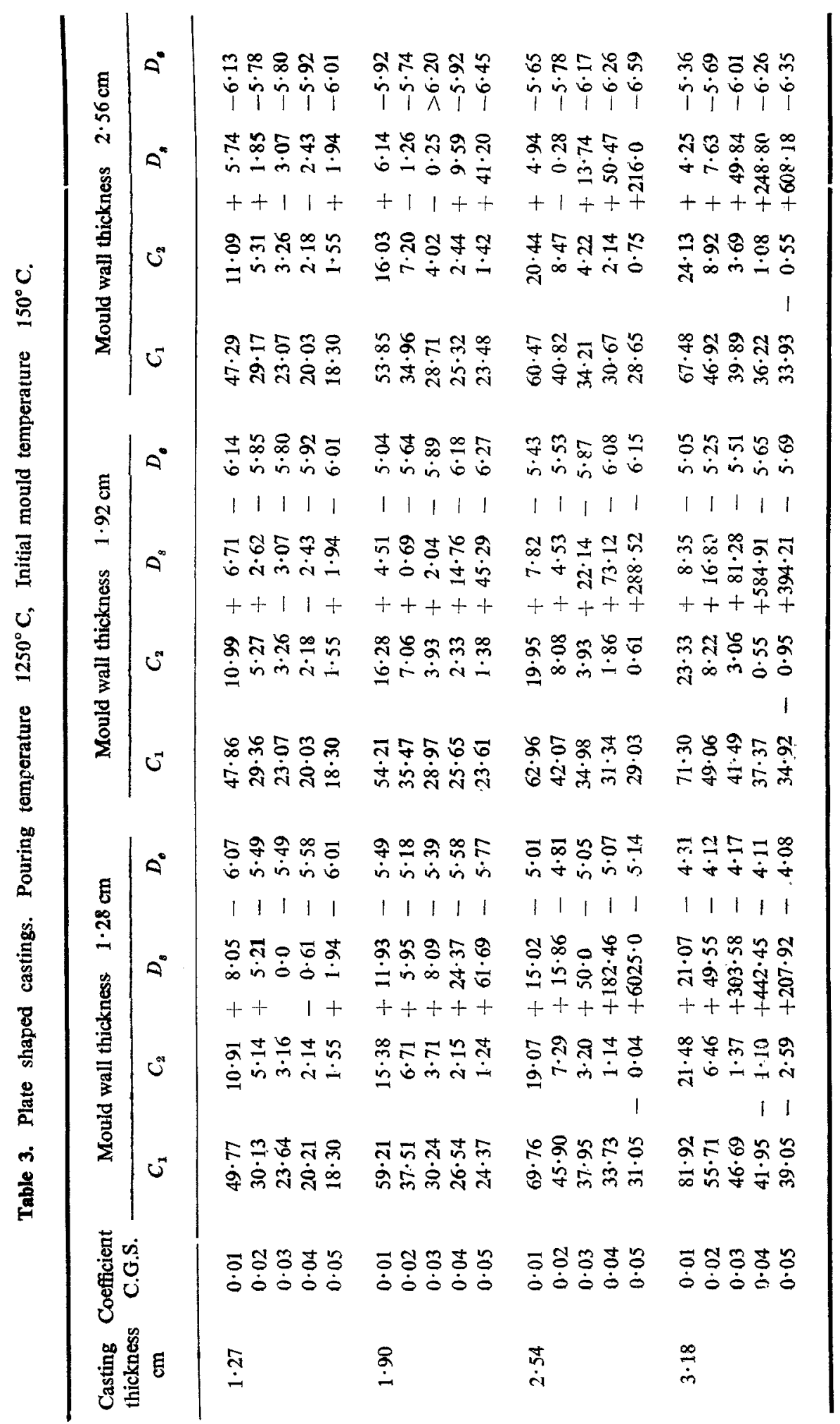




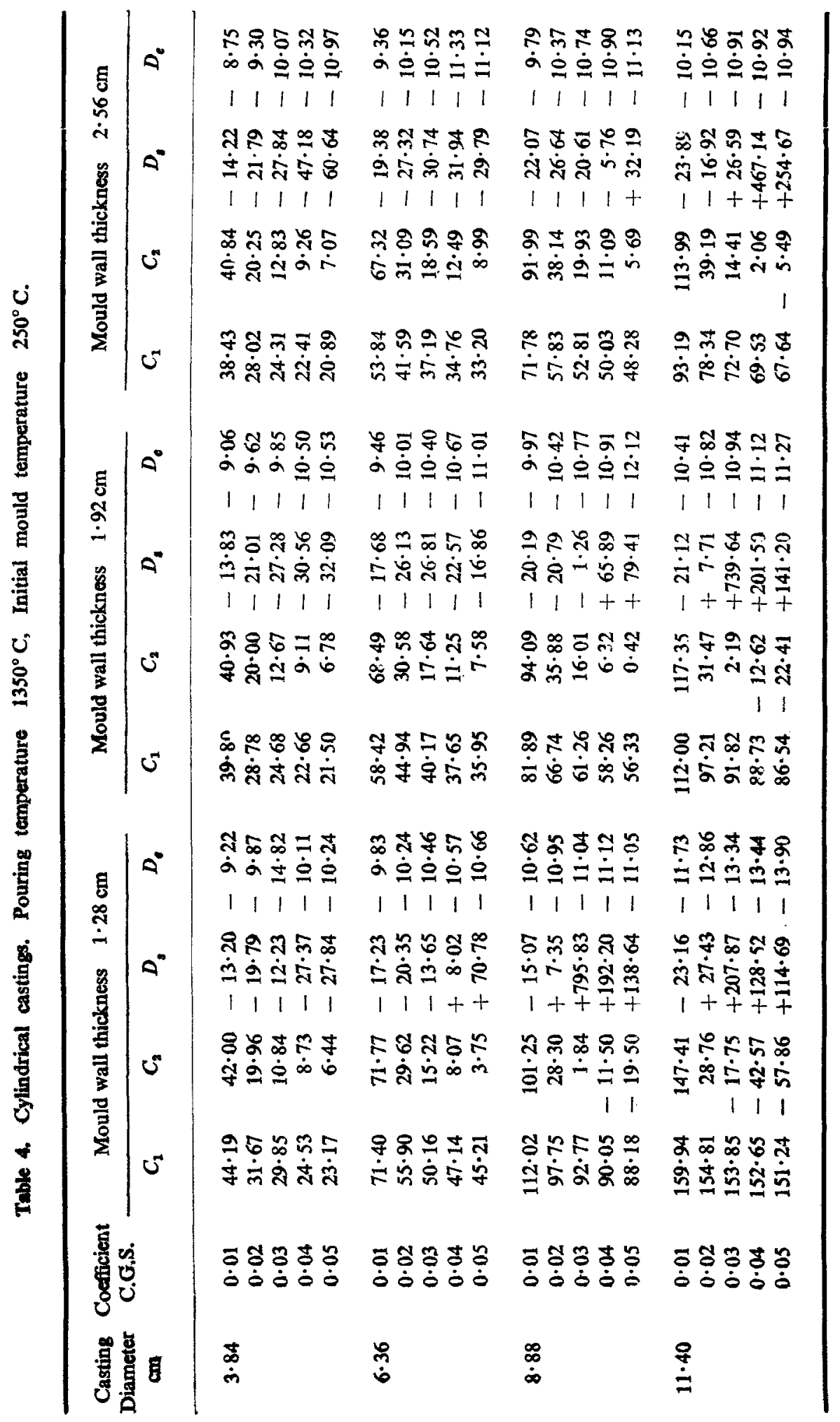




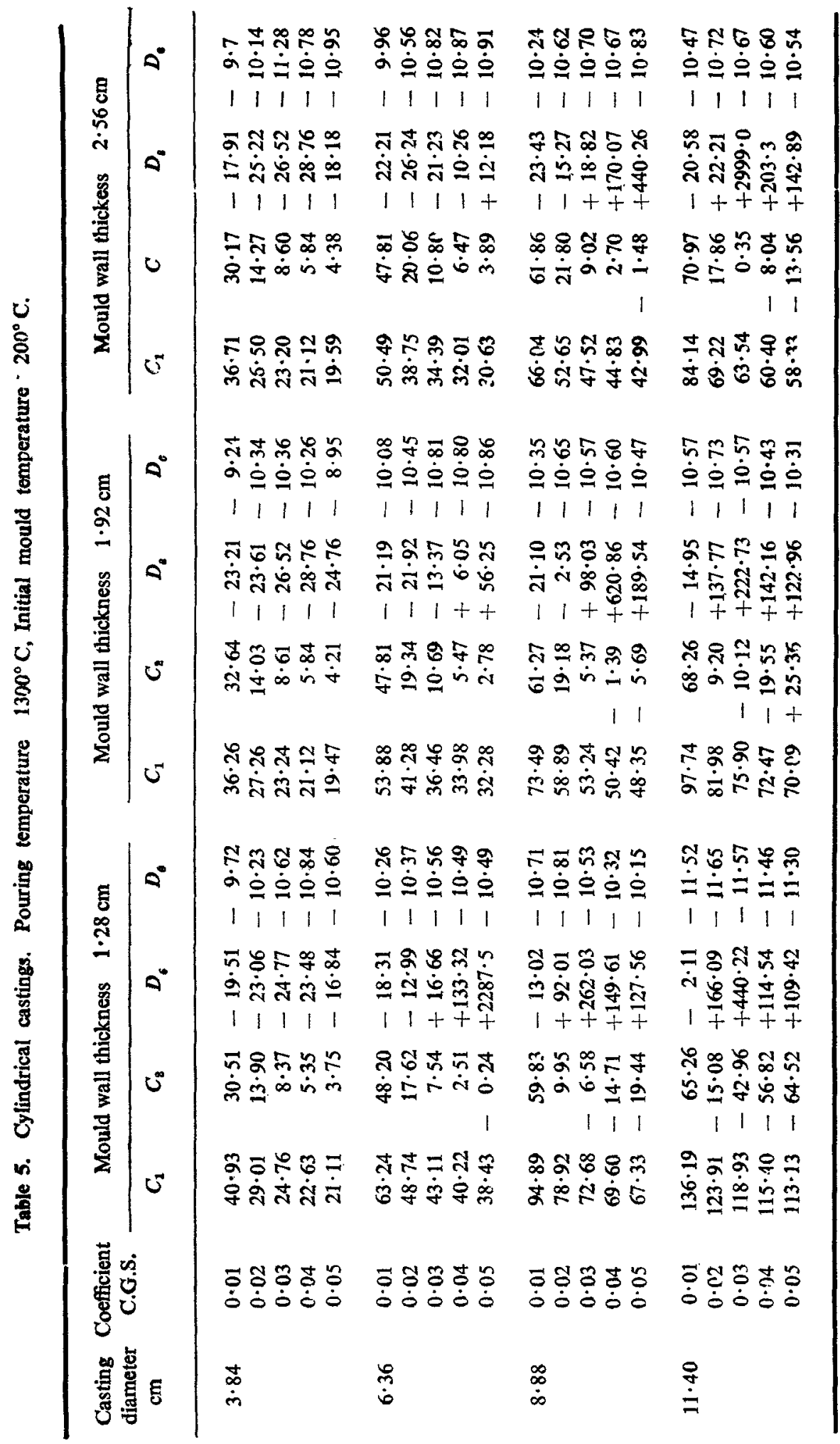




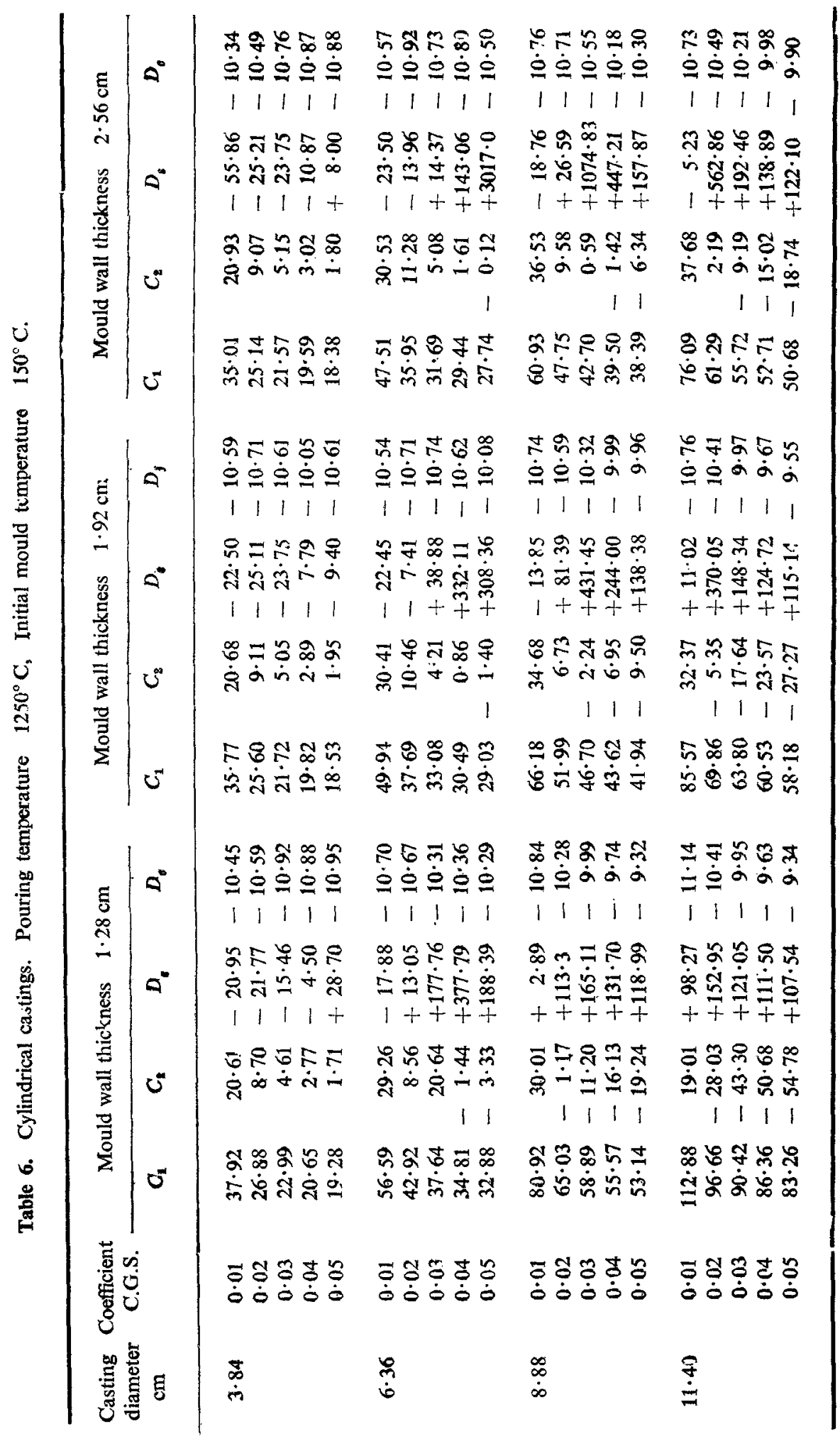


and the centre of each casting from the predicted value using this relationship have also been listed in the tables. Here,

$$
D_{0}=\frac{T_{0}-T_{\text {cot (coniro) }}}{T_{0}} \times 100,
$$

and $\quad D_{s}=\frac{T_{s}-T_{\text {aet (surfaea) }}}{T_{s}} \times 100$.

From the information provided in the tables it is thus possible to calculate the local solidification times at different locations of each "casting". The calculated values are no doubt approximate in the interior regions but this method provides a generalised treatment for all the "castings" examined despite differences in the shape of solidification time-location curves.

It may be observed from the tables that the deviation coefficients at the centre of the casting are always negative, implying that the solidification time-location curve "dips" at the centre in all cases. On the other hand, the deviation coefficients at the surface of the casting may either be negative or positive depending upon the processing conditions. Physically however, positive deviations are much more significant than negative deviations as observed typically in figure 3 .

Further, the deviation cefficients at the centre of the casting vary over fairly narrow ranges both in the case of plates (abut 2-6.5\%) and cylinders (about $8 \cdot 5-14 \%$ as opposed to variation over extremely large ranges of deviation coefficients at the surfac. Very large values of $D_{s}$ are obtained when $T$-intercept values are small.

\section{Application of lacal solidification time}

The application of local solidification time for assessment of such microstructural features as dendrite-arm spacing is too well-known to be discussed here. It will be shown in this paper that these values may be usefully employed to predict the gross microstructural features at different locations of the "castings" considered in the present work and to estimate the tensile strength of the "castings" at these locations. Chill-free grey iron cast in metallic moulds may have undercooled and/or flake gräphite associated with ferritic and/or pearlitic matrix in different combinations at different locations. The consequence of this type of microstructure would be differences in mechanical behaviour at different locations. With prior knowledge of the microstructural features however, it would be possible to have a better understanding of the mechanical behaviour of the casting under service conditions. Knowledge of local solidification times of the casting would be extremely useful in this respect.

In figure 4 is shown the relationship between the solidification time, the dimensions of the casting and the microstructural features and in figure 5 the relationship between the solidifization times and the tensile strength in respect of permanent mould chill-free grey iron castings (Rama Prasad et al 1980). where the casting geometry and the processing conditions are-similar to those assumed in the present work. It is evident from these figures that it is possible to predict the type of graphite and the matrix to estimate the tensile strength of such castings 


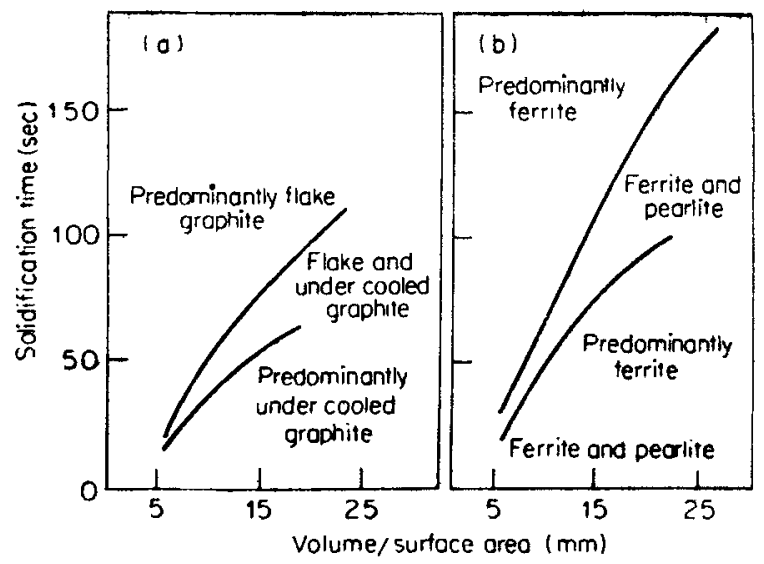

Figure 4. Variation in graphite and matrix structure in grey cast iron.

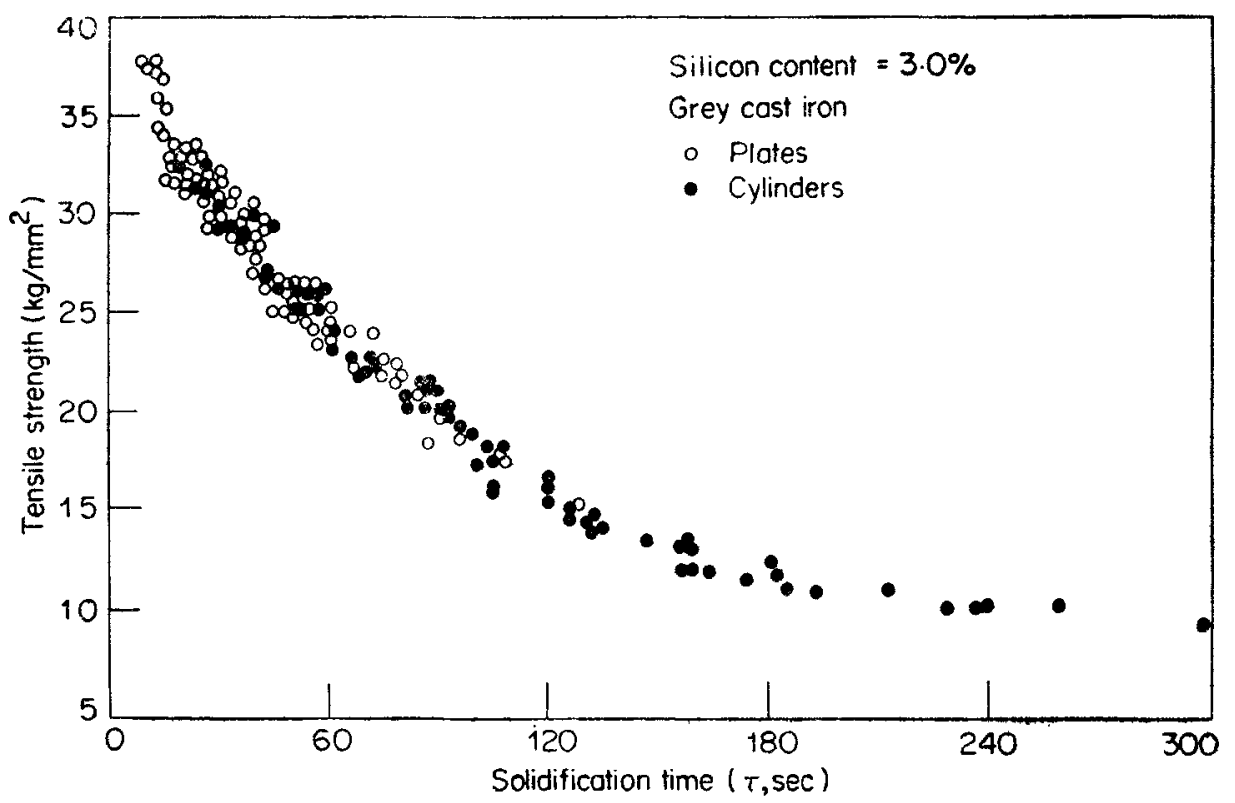

Figure 5. Tonsile strength versus solidification time.

from a knowledge of the solidification time. Also from a knowledge of local solidifization times as computed in this work it should be possible to make a reasonably good prediction of the microstructural features at a given location in such permanent mould grey iron castings and to estimate the tensile strength at that location. For example, the "casting" which has the largest total solidification time (about $935 \mathrm{sec}$ ) among those examined in the present work is a cylinder with $11.40 \mathrm{~cm}$ diameter. This has been "cast "into a mould of $1.28 \mathrm{~cm}$ wall thickness at a pouring temperature of $1350^{\circ} \mathrm{C}$ and initial mould temperature of $250^{\circ} \mathrm{C}$, the heat transfer coefficient at the casting-mould interface being 

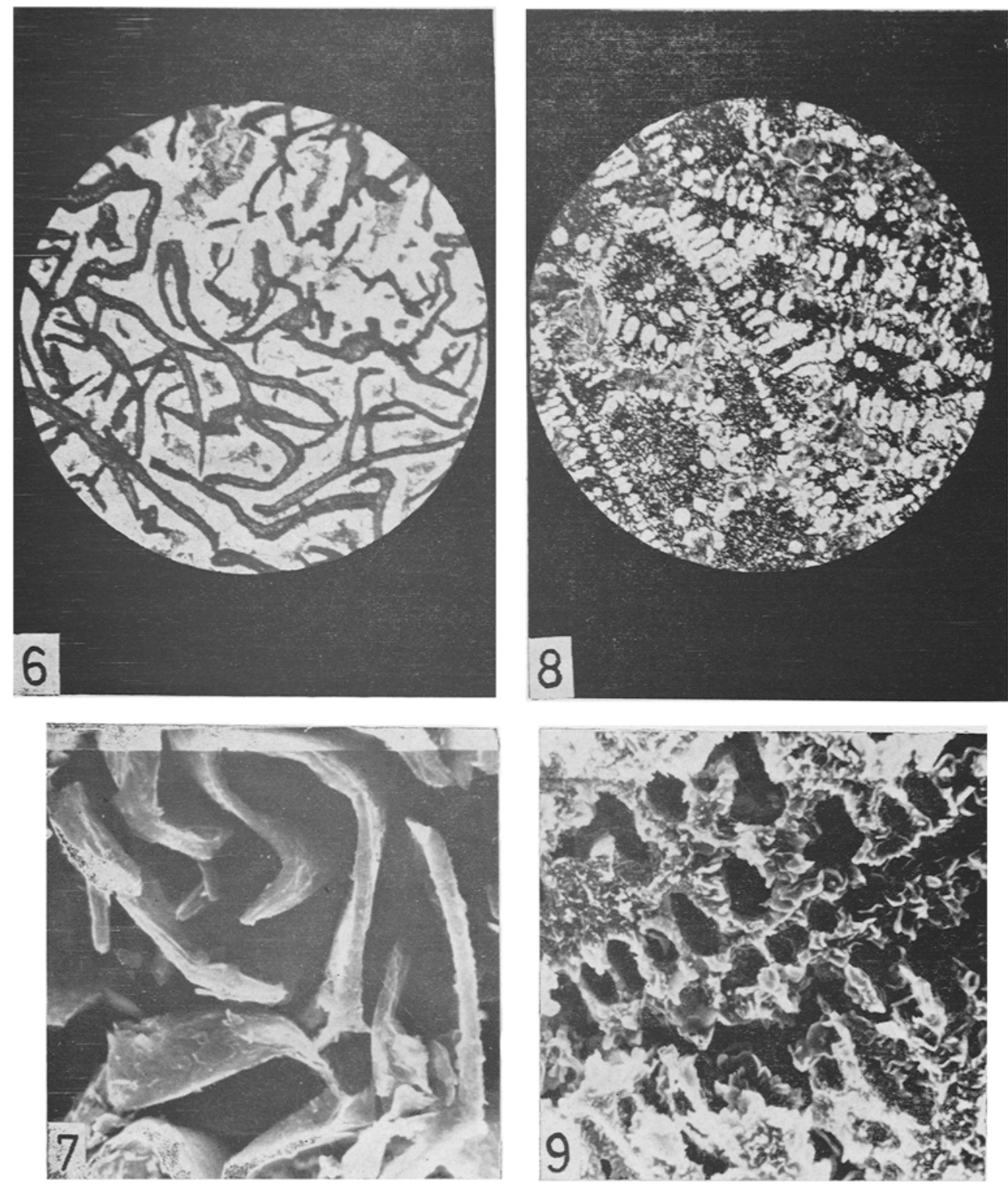

Figure 6-9. 6. Optical ihotomicrograph showing flake graphite in a matrix predominantly of ferrite $(\times 100)$. 7. Scanning electron microscope showing flake graphite $(\times 420)$. 8. Optical photomicrograph showing undercooled graphite in a matrix predominantly of ferrite. 9. Scanning electron microscope showing undercooled graphite ( $(420)$. 
0.01 C.G.S. units (the value of the latter would be attainable with a thick layer of highly insulating mould coating). The volume-to-surface area ratio of this "casting" is $2 \cdot 85 \mathrm{~cm}$. Reference to figure 4 indicates that this "casting" could be expected to have coarse flake graphite in a matrix predominantly of ferrite at the centre, a typical microstructure which may correspond to this condition being shown in figure 6. The features of graphite are shown in greater detail in figure 7, which is a scanning electron micrograph of flake graphite. Further, reference to figure 5 shows that the tensile strength of this "casting" at the centre may be expected not to exceeed $10 \mathrm{~kg} / \mathrm{mm}^{2}$.

Also, with reference to table 4 it may be computed that the local solidification time of this "casting" at the surface is about 113 seconds. Figures 4 and 5 make it clear that the structure and strength at this location would be similar to those at the centre. Thus a "casting" such as this would have the same type of graphite and matrix, and would have uniformly poor tensile strength throughout.

If now the pouring temperature of this "casting" is reduced to $1250^{\circ} \mathrm{C}$, the initial mould temperature to $150^{\circ} \mathrm{C}$, and the metal is poured into a mould with $2 \cdot 56$ wall thickness coated with a thin layer of mould coating so as to increase the heat transfer coefficient to 0.05 C.G.S. units, the total solidification time would be reduced to $244 \mathrm{sec}$ (table 4). Figures 4 and 5 indicate that the structure in the central region would consist of flake graphite in a matrix of ferrite and that the tensile strength in this region would not exceed $10 \mathrm{~kg} / \mathrm{mm}^{2}$. However, the local solidification time at the surface would now be only about $4 \mathrm{sec}$ which would mean that the microstructure here will consist of undercooled graphite in a matrix

Table 7. Probable microstructure and tensile strength at different locations in a $11.5 \mathrm{~cm}$ dia " casting".

\begin{tabular}{|c|c|c|c|}
\hline \multirow{2}{*}{$\begin{array}{l}\text { Location } \\
\text { (rofer } \\
\text { figure 1) }\end{array}$} & \multicolumn{2}{|c|}{$\begin{array}{c}\text { Predicted } \\
\text { Microstructure }\end{array}$} & \multirow{2}{*}{$\begin{array}{l}\text { Estimated } \\
\text { ultimate } \\
\text { tensile } \\
\text { strength } \\
\mathrm{kg} / \mathrm{mm}^{2} \\
\text { (approx.) }\end{array}$} \\
\hline & Type of graphite & Type of matrix & \\
\hline 6 & Undercooled & $\begin{array}{l}\text { Ferrite } \\
\text { (with probably } \\
\text { small amount } \\
\text { of pearlite) }\end{array}$ & $40 \cdot 0$ \\
\hline 5 & Flake + undercooled & Ferrite & $30 \cdot 0$ \\
\hline 4 & Flake + undercooled & Ferrite & $22 \cdot 5$ \\
\hline 3 & Flake & Ferrite + pearlite & $15 \cdot 0$ \\
\hline 2 & Flake & Ferrite + pearlite & $12 \cdot 5$ \\
\hline 1 & Flake & Ferrite & $10 \cdot 0$ \\
\hline 0 & Flake & Ferrite & $10 \cdot 0$ \\
\hline
\end{tabular}

Pouring temp. $1250^{\circ} \mathrm{C}$; initial mould temp. $150^{\circ} \mathrm{C}$; mould wall thickness $2.56 \mathrm{~cm}$ and $h=0.05$ CGS units. 
of ferrite (with probably a small amount of pearlite). In figure 8 is shown a typical optical photomicrograph which may correspond to this condition, while in the scanning electron micrograph shown in figure 9 details of undercooled graphite are clearly visible. Figure 5 indicates that the tensile strength at the surface in this case could be expected to be in the region of $40 \mathrm{~kg} / \mathrm{mm}^{2}$, a fourfold increase over the previous case. The structure and tensile strength at the interior would gradually change according to changes in local solidification time. The expected microstructural features and tensile strength at different locations in this "casting" are summarised in table 7.

It is to be appreciated however, that many microscopic events are involved in solidification and therefore the effectiveness of the present approach in practical situations will be governed by the extent to which the consequences of these events are reflected in the bulk conduction cooling rate of the castings.

\section{Acknowledgement}

The author would like to thank the University Grants Commission, Government of India for providing a grant for computational work.

\section{List of symbols}

$$
\begin{aligned}
& A T \quad \text { ambient temperature } \\
& C \quad \text { nodal point at the outer surface of the casting } \\
& C_{p} \quad \text { specific heat }\left(\mathrm{cal} / \mathrm{g}^{\circ} \mathrm{C}\right) \\
& C_{1}, C_{2} \quad \text { slope and intercept in the equation } T=C_{1} l+C_{2} \\
& D \quad \text { nodal point at the inner sutface of the mould } \\
& D_{0} \quad \text { deviation coefficient at the centre of the casting } \\
& \text { D. deviation coefficient at the surface of the casting } \\
& h \text { heat transfer coefficient at the casting-mould interface (cal/ } / \operatorname{sec~}^{2}{ }^{\circ} \mathrm{C} \text { ) } \\
& \boldsymbol{h}_{C, B} \quad \text { heat transfer coefficient due to convection and radiation (cal } / \mathrm{sec} \mathrm{cm}^{2}{ }^{\circ} \mathrm{C} \text { ) } \\
& I \text { nodal point in the interior of the casting and the mould } \\
& K \text { thermal conductivity, (cal } / \mathrm{sec} \mathrm{cm}^{2}{ }^{\circ} \mathrm{C} \text { ) } \\
& L \quad \text { nodal point at the outer surface of the mould } \\
& M \quad \text { modulus } a \frac{\Delta t}{(\triangle X)^{2}} \text { or } a \frac{\Delta t}{(\triangle r)^{2}} \\
& \theta N \quad \text { temperature at time } t+\Delta t \\
& r \quad \text { radius of cylindrical castings }(\mathrm{cm}) \\
& T \quad \text { local solidification time in the interior of the casting }
\end{aligned}
$$


$T_{0} \quad$ solidification time at the centre of casting predicted by $T=C_{1} l+C_{2}$

T. Solidification time at the surface of the casting predicted by $T=C_{1} l+C_{2}$

$T_{\text {act }} \quad$ actual solidification time at a given location

$\triangle t \quad$ time increment (sec)

$l$ distance of interior nodal point from the outer surface of the casting

$t \quad$ time (sec)

$X \quad$ thickness of plate castings (cm)

a thermal diffusivity $(K / C, \rho)\left(\mathrm{cm}^{2} / \mathrm{sec}\right)$

$\rho \quad$ density $(\mathrm{gm} / \mathrm{cc})$

$\theta \quad$ temperature at time $t\left({ }^{\circ} \mathrm{C}\right)$

$\Delta X, \Delta r \quad$ spatial increment (cm).

\section{References}

Angus H T 1960 Physical and engineering properties of cast iron (British Cast Iron Iron Ros. Assoc. Alvechurch)

Dusinberre G M 1949 Numerical analysis of heat flow (New York : McGraw-Hill)

Eyres W R, Hartree D R, Ingham J, Jackson R, Sarjant R J and Wagstaff J B 1946 Philos. Trans. R. Soc. (London) 240A 1

Rama Prasad M S 1976 Solidification structure and strength of permanent moulded cast iron Ph.D. Thesis, Indian Institute of Science, Bangalore

Rama Prasad M S, Narendranath C S and Srinivasan M N 1980. Presented at the conference on Solidification in the foundry and cast house, Metals Society of the Iron and Stool Institute UK at the University of Warwick

Srinivasan M N 1975 Cast Metal Res. J. 1191 